\title{
KAJIAN TEOLOGIS TENTANG PENDIDIKAN AGAMA KRISTEN DALAM ALKITAB
}

\author{
Steven Tubagus \\ Sekolah Tinggi Teologi Injili Setia Siau \\ tubagussteven@gmail.com
}

\begin{abstract}
With the development of liberal theology in the 18-19 century AD, there was an opinion that Christian Education was not in the Bible. This research aims to describe the study of the existence of Christian Education in the Bible. The method used is qualitative with a literature study. The research results are as follows: First, Christian Education in the Bible already exists in the Old Testament. God revealed Himself to the Israelites and gave teachings through the prophets. Second, the Old Testament centers on God's law, and God gave the Ten Commandments to the people of Israel as a basis for education. Third, in the New Testament of Jesus, Jesus' disciples and the early church always gave teachings as a manifestation of God's intervention.
\end{abstract}

Keywords: Christian Education, Bible

\begin{abstract}
Abstrak. Seiring berkembangnya teologi liberal pada abad 18-19 M, ada pendapat yang muncul bahwa Pendidikan Agama Kristen tidak ada dalam Alkitab. Tujuan penelitian ini adalah untuk mendeskripsikan kajian tentang keberadaan Pendidikan Agama Kristen dalam Alkitab. Metode yang digunakan adalah kualitatif dengan studi pustaka. Hasil penelitian adalah sebagai berikut: Pertama, Pendidikan Agama Kristen di dalam Alkitab sudah ada dalam Perjanjian Lama di mana Allah menyatakan diri kepada bangsa Israel dan memberikan pengajaran melalui para nabi. Kedua, Perjanjian Lama berpusat pada hukum Allah, dan Allah telah memberikan Sepuluh Hukum Taurat kepada umat Israel sebagai dasar pendidikan. Ketiga, dalam Perjanjian Baru Yesus, murid-murid Yesus, dan juga jemaat mula-mula selalu memberikan pengajaran sebagai wujud dari intervensi Allah.
\end{abstract}

Kata kunci: Pendidikan Agama Kristen, Alkitab

\section{PENDAHULUAN}

Teologi liberal mulai muncul dan berkembang pada abad 18-19M. Salah satu hal yang menandai perkembangan tersebut adalah kontroversi mengenai mengenai keberadaan Pendidikan Agama Kristen (PAK) dalam Alkitab. Ada berpendapat bahwa PAK tidak ada dalam Alkitab. Hal ini tentu sesuai dengan kenyataan yang sebenarnya mengenai Alkitab. Sehingga pendapat demikian dapat 
BONAFIDE: Jurnal Teologi dan Pendidikan Kristen

www.jurnal.sttissiau.ac.id/Volume 1/Nomor 2/Desember 2020/hal. 180-196

disejajarkan dengan ateisme dan penyembahan berhala yang melawan Kekristenan.(Frame 2009)

Belajar merupakan proses yang meningkatkan kemungkinan seseorang untuk mendapatkan serta membentuk sikap, keterampilan, dan kompetensi baru. Prosesnya melibatkan mental internal yang terjadi karena pengalaman, latihan, dan interaksi sosial. Hasil belajar ditunjukkan oleh terjadinya perubahan perilaku yang bersifat relatif permanen. (Khodijah 2018).

Jemaat mula-mula sangat menjunjung pengajaran agama. Awalnya mereka masih mengikuti tradisi Yahudi, tetapi lambat laun belajar mereka mengembangkan tradisi sendiri melalui perkumpulan-perkumpulan yang mereka buat. Dalam perkumpulan tersebut mereka belajar berdoa dan membicarakan tentang pengajaran dan perbuatan-perbuatan Yesus Kristus. Mereka juga belajar berkhotbah dan mengajar supaya makin banyak orang lain yang ikut percaya kepada Yesus.

Kerajinan dan kesetiaan Israel dalam menjalankan pendidikan agama mereka turuti pula. Bedanya sekarang yang menjadi dasar dan pusat pendidikan mereka bukan hukum Taurat melainkan Yesus Kristus. Mereka mengajarkan agama Kristen di tengah keluarga, dalam kebaktian, dan siapa saja. Ini merupakan bukti bahwa PAK ada dalam Alkitab. Sebab itu penulis ingin mengeksplorasi keberadaan PAK di dalam Alkitab untuk menguatkan gagasan bahwa PAK pada hakekatnya memiliki dasar di dalam Alkitab.

\section{METODE PENELITIAN}


Metode yang digunakan dalam penelitian ini adalah kualitatif dengan pengumpulan data melalui studi pustaka. Studi pustaka, menurut Supriyadi, adalah serangkaian kegiatan pengumpulan data dengan membaca, mencatat, serta mengolah bahan penelitian. (Supriyadi 2016). Penulis menggunakan berbagai literatur primer dan sekunder berkaitan dengan topik pembahasan. Cara ini mempermudah untuk mengambil kesimpulan dari hasil pembahasan yang sesuai dengan maksud teks dan konteks aslinya.

\section{HASIL PENELITIAN}

Jemaat Kristen mula-mula menempatkan pendidikan agama sebagai hal penting dalam kehidupan mereka. Tugas mengajar diserahkan kepada para guru yang mempunyai karunia dan telah terlatih, tetapi jemaat tetap memberikan dukungan dan doa bagi mereka. Sejak awalnya pendidikan agama Kristen mempersiapkan orang untuk memasuki persekutuan jemaat Kristus. Setelah disambut dalam jemaaat, mereka terus dididik untuk semakin berakar dalam pengetahuan dan pengenalan akan Yesus Kristus. Jika hubungan guru dan siswa dapat dijaga dengan baik dan dilakukan secara sinergis, maka usaha memenuhi tujuan pendidikan bukanlah hal yang sukar. Guru adalah teman, filsuf dan panutan bagi siswa. Seorang guru adalah motivator yang terbaik, seorang pecinta, pengisi kekuatan, dan penyemangat.(Djihad 2012)

Perkembangan Pendidikan Agama Kristen pada zaman Para Rasul menyerupai gaya dan metode pengajaran Yesus. Para murid memberitakan Injil dengan memiliki kemampuan menafsirkan, melakukan mujizat, mengajarkan 
BONAFIDE: Jurnal Teologi dan Pendidikan Kristen

www.jurnal.sttissiau.ac.id/Volume 1/Nomor 2/Desember 2020/hal. 180-196

perumpamaan dan kasih. Bahkan setiap kali Injil diberitakan semakin banyak orang yang percaya oleh karena perbuatan-perbuatan ajaib yang dilakukan muridmurid pada zaman itu. Hasilnya banyak orang percaya memakai metode yang terapkan Yesus sehingga banyak orang bertobat, percaya Yesus dan menerima Yesus sebagai Tuhan dan Juru selamat. (Utomo 2017). Usaha pendidikan agama Kristen perlu mencakup pengetahuan dan pengertian firman Allah juga, khususnya yang berupa Alkitab. Kalau Alkitab tidak dipahaminya, maka semua macam ketakhyulan dapat masuk ke dalam kehidupan orang kristen. Tetapi dengan Alkitab ketakhyulan dan maksud Iblis yang buruk selalu dapat dikalahkan.(R. R. Boehlke 2016)

Yang jelas mereka memperoleh suatu gaya hidup dan adat istiadat Kristen yang mencerminkan pedoman-pedoman Kerajaan Allah. Suatu sikap hidup yang dapat membantu orang-orang yang "lemah" di dalam usahanya memutuskan hubungannya dengan adat istiadat dan kebiasaan yang lama. Suatu sikap hidup yang di dalam lingkungan kita dapat berarti sebagai suatu seruan yang tegas, supaya orang bertobat dan membuang segala takhayul, sihir, dan penyembahan berhala. Dengan demikian akan terwujudlah pembangunan di mana masyarakat kita maju setapak demi setapak. (Verkuyl 2012)

Hasilnya ialah bahwa ajaran tentang PAK mengandung panggilan dan pemberitaan yang ditujukan kepada hidup kita di masa kini dan disini: agar kita benar-benar hidup sesuai dengan kehendak Allah, maka kita disuruh memandang kepada Kristus dan disuruh masuk kedalam persekutuan baru yang Ia sendiri menjadi kepalanya. (Niftrik 2008) 
BONAFIDE: Jurnal Teologi dan Pendidikan Kristen

www.jurnal.sttissiau.ac.id/Volume 1/Nomor 2/Desember 2020/hal. 180-196

\section{PEMBAHASAN}

\section{Sejarah Pendidikan Agama Kristen}

Sejarah adalah laporan mengenai peristiwa-peristiwa aktual yang terjadi di masa lampau secara tertulis beberapa waktu kemudian setelah peristiwa itu berlangsung. Keistimewaan dari laporan-laporan tertulis ini ialah keterangan yang disampaikannya tetap terpelihara dari generasi ke generasi dalam bentuk yang tepat sebagaimana dimulanya ditulis. Penulis-penulis yang kemudian dapat menambahkan hal-hal yang yang baru pada laporan ini, namun tidak mengubah cerita itu sendiri sehingga valid dan dapat dipercaya. (Hinson 2004)

Pendidikan Agama Kristen sudah ada dalam Perjanjian Lama dimana Allah menyatakan diri kepada bangsa Israel dan Allah mengajarkan mereka melalu para nabi. Dalam Kejadian 2:19-20 pendidikan pertama diberikan kepada Adam dan hawa, lalu dalam Kej 12:1-9 Abraham menjadi bapa orang percaya. Dalam Keluaran 21:12, Tuhan berfirman kepada Musa: "naiklah menghadap Aku, keatas gunung, dan tinggallah disana, maka Aku akan memberikan kepadamu loh batu, yakni hukum dan perintah, yang telah Kutuliskan untuk diajarkan kepada mereka". Sepuluh hukum Taurat ini kemudian diajarkan kepada bangsa Israel sehingga kehidupan mereka berkembang. Dengan begitu Musa dapat memohon kepada Tuhan agar umat Israel tidak mendapatkan penghukuman, melainkan pengampunan dosa, serta menjadikan mereka harta pusaka dan kepunyaan-Nya sendiri. (Carson 1997).

PAK merupakan sebuah usaha yang dilakukan secara sadar dan juga terencana dalam rangka meletakkan dasar Yesus Kristus ( 2Kor. 3:13) di dalam 
BONAFIDE: Jurnal Teologi dan Pendidikan Kristen

www.jurnal.sttissiau.ac.id/Volume 1/Nomor 2/Desember 2020/hal. 180-196

pertumbuhan iman Kristen. Cara yang ditempuh adalah menciptakan suasana dan proses pembelajaran yang memungkinkan peserta didik menjadi aktif untuk mengembangkan potensinya. Harapannya dengan itu peserta didik akan memiliki kekuatan spritual yang menjadi landasan bagi pengendalian diri, kepribadian, kecerdasan, akhlak mulia, serta keterampilan yang perlukan dirinya dan masyarakat. Oleh karena Kristen adalah pengikut Kristus, Pendidikan Agama Kristen meletakkan dasar pengajarannya pada pengajaran dan tindakan Yesus Kristus. (Harianto 2012)

PAK dalam Alkitab adalah dasar yang penting untuk dikembangkan sebagai pusat proses pembelajaran. Umat Kristen mula-mula melakukan ini dalam kehidupan mereka sehari-hari. Di tengah berbagi kekurangan dan kesulitan yang mereka hadapi pada waktu itu, meskipun mereka hanya kelompok kecil di tengah lingkungan yang bukan Kristen, tetapi mereka bisa menjalankan PAK dalam kehidupan sehari-hari. Hal ini seperti perkataan Paulus bahwa di tengah-tengah angkatan yang bengkok hatinya dan sesat ini, jemaat Kristen bercahaya seperti bintang-bintang di dunia (Fil. 2:15).(Berkhof 2004)

Amanat Agung Tuhan Yesus adalah dasar pokok PAK, di mana para murid Yesus diberikan perintah untuk mengajar dan memberitakan Injil kepada semua orang. Belajar merupakan proses untuk mendapatkan pengetahuan, meningkatkan kemampuan, dan mengubah tingkah laku. Perubahan tingkah laku sendiri adalah perubahan terjadi secara sadar, bersifat kontinyu, fungsional, positif, dan aktif.(Simanjuntak 2017) Dalam hal perilaku, manusia harus terus belajar agar mewujudkan hakekatnya sebagai gambar Allah. Dalam hidupnya - 
BONAFIDE: Jurnal Teologi dan Pendidikan Kristen

www.jurnal.sttissiau.ac.id/Volume 1/Nomor 2/Desember 2020/hal. 180-196

manusia harus mencerminkan dan memantulkan cahaya kemuliaan Tuhan Allah. (Brotosudarmo 2007)

Yesus adalah contoh tentang peluang yang terbuka bagi seseorang yang mengejawantahkan kesatuannya dengan Allah yang Esa. Ada pendapat yang mengatakan bahwa walaupun Yesus dinamakan anak Allah, namun tabiat ilahi tidak tersirat didalam-Nya. Kesimpulan ini menggangu orang Kristen, karena di dalamnya tidak ada unsur kenabian dan juga pelayanan pokok yang dilambangkan oleh peristiwa yang terjadi di Golgota dan dalam kubur yang kosong. Juruselamat tidak ada memerlukan apa-apa, karena manusia tidak bertabiat dosa. Manusia berbuat salah karena hasil pendidikan yang kurang baik. Percaya Yesus berarti hidup intim dengan Allah sama seperti Yesus hidup menyatu dengan Allah. walaupun penjelasan itu tidak memuaskan umat Kristen, namun dengannya mereka ditantang untuk memperluas apa artinya menjadi percaya itu. Menurut teologi Froebel, percaya berarti mengikuti Yesus dalam usaha-Nya, melaksanakan kehendak-Nya.(Robert R Boehlke 2016)

\section{Perjanjian Lama}

PAK dalam Perjanjian Lama hingga masa abad pertengahan, berakar pada kebudayaan Yunani, Romawi, maupun Yahudi. Sokrates merupakan salah satu filsuf yang memberi pengaruh terhadap pendidikan Kristen, yaitu metode belajar menjernihkan pikiran melalui pertanyaan yang semakin mendalam. Kemudian muridnya, Plato, dimanfaatkan pemimpin Kristen untuk menyoroti intisari pendidikan. Penerusnya, Aristoteles, mengajar gereja bagaimana menggolongkan pengetahuan agar lebih gampang memperolehnya bilamana diperlukan kembali. Ia 
BONAFIDE: Jurnal Teologi dan Pendidikan Kristen

www.jurnal.sttissiau.ac.id/Volume 1/Nomor 2/Desember 2020/hal. 180-196

menunjukkan bagaimana akal manusia digunakan untuk mempertimbangkan bobot sejumlah usaha manusia, termasuk di bidang pendidikan. Semua pendidikan diarahkan kepada pengembangan pribadi agar memiliki kemampuan mengetahui hubungan-hubungan antara segala sesuatu serta bertindak sesuai dengan pengetahuan tersebut. Seandainya segala sesuatu terdapat di dalam dunia ini berdiri sendiri-sendiri, yang satu lepas dari pada yang lain, tanpa saling berhubungan, didunia ini tentu tidak akan ada ilmu pengetahuan, sebab ilmu pengetahuan adalah saling berbuhungan satu dengan yang lain. (Hadiwijono 2003)

Kecaman Israel yang mewarnai seluruh Perjanjian Lama adalah suatu petunjuk penting bagi asal mula dan tujuan penulisannya. Perjanjian Lama bukanlah karya sastra nasional bangsa Israel kuno, melainkan kumpulan kitab keagamaan. Ia mungkin karya sekelompok kecil dari orang yang dari satu generasi ke generasi yang berikutnya, memberikan kesaksian iman mereka kepada Allah, dan seringkali dengan resiko tidak disetujui oleh penguasa, ditindas dan bahkan dihukum mati. Dalam hal studi Perjanjian Lama ada satu kesulitan tambahan. Apabila kita mempunyai suatu pengetahuan tantang Perjanjian Lama, kemungkinan besar pengetahuan itu kita peroleh dari dari gereja atau sekolah.(Rogerson 2011)

Namun demikian, tradisi Alkitab tak dapat disangkal menekankan asal pengajaran hikmat itu dari kota yang satu. Salomo berulangkali ditonjolkan sebagai guru hikmat dan pengarang kitab-kitab hikmat yang pertama. Dialah yang mulai memanggil orang-orang bijak untuk menjadi penasehatnya atau guru-guru untuk membina anak-anak raja dan calon-calon pegawai kerajaan, maka 
BONAFIDE: Jurnal Teologi dan Pendidikan Kristen

www.jurnal.sttissiau.ac.id/Volume 1/Nomor 2/Desember 2020/hal. 180-196

berkembanglah istana di Yerusalem sebagai pusat pemikiran, pencerahan dan pendidikan. Dari lingkaran "dalam" ini meresaplah pengaruh hikmat itu ke segala lapisan masyarakat. Seluruh kota Yerusalem mulai turut serta di dalam gerakan pembaharuan budi dan perilaku berdasarkan ajaran-ajaran hikmat. Makanya kota kerajaan itu menjadi penyuluh dan perintis jalan bagi segala kota, desa atau pelosok di sekitarnya: suatu perangsang bagi seluruh umat Israel, malah bagi semua bangsa yang lain. Mengingat besarnya anugrah yang pernah diterimanya, maka sungguh sepatutnya Yerusalem disebut "pusat pengajaran hikmat".(Barth 2009)

PAK dalam Perjanjian Lama berpusat pada hukum Allah dan kurban melalui sistem imamat. Allah memberikan Sepuluh Hukum Taurat kepada umat Israel (Keluaran 20:1-17) dan perintah untuk mengasihi-Nya (Ulangan 6:4-9). Ia juga memberikan berbagai aturan mengenai tata ibadah dan hubungan sosial di antara mereka. Perjanjian Lama mengajar umat Israel bersandar pada anugerah Allah melalui sistem kurban. Melalui hukum Taurat, mereka disadarkan bahwa sebagai orang berdosa mereka memerlukan anugerah pengampunan Allah. Dengan demikian jelas bahwa PAK dalam Perjanjian Lama sebenarnya menyiapkan umat Israel menyambut kedatangan Yesus Kristus sang Mesias. Pendidikan Kristen mestinya membekali peserta didik dengan kecakapan memberitakan firman Tuhan dan mengembangkan pengetahuan dan spritual mereka yang takut akan Tuhan. (Sairin 2011)

Allah sendiri bertindak sebagai memprakarsa dan pengajar utama pendidikan agama dalam Perjanjian Lama, "ketika Israel masih muda, Kukasihi 
BONAFIDE: Jurnal Teologi dan Pendidikan Kristen

www.jurnal.sttissiau.ac.id/Volume 1/Nomor 2/Desember 2020/hal. 180-196

dia, dan dari Mesir Kupanggil AnakKu itu ... Akulah yang mengajar Efraim berjalan dan mengangkat mereka di tangan- $\mathrm{Ku}$, tetapi mereka tidak mau insaf, bahwa Aku menyembuhkan mereka. Jadi agama merupakan semacam ilmu sakral yang secara khusus dipelajari oleh para murid, sekaligus sebagai persiapan untuk memimpin jemaat sakral dikemudian hari.(Schumann 2015)

Metode penyampaian PAK dalam PL, kepala keluarga merupakan pihak yang paling bertanggung jawab dalam mengajarkan pendidikan agama kepada keluarganya. PAK yang demikian sudah dimulai dari terpanggilnya Abraham menjadi nenek moyang umat pilihan Tuhan. Ini merupakan pola pendidikan di sekolah-sekolah Yahudi yang menggunakan metode hafalan. Anak laki-laki umur 6 tahun sudah mulai mempelajari huruf-huruf Ibrani sehingga pada umur 10 tahun sudah mampu membaca PL dalam bahasa Ibrani. Setelah itu mereka melanjutkan sekolah Beth Talmud untuk mempelajari Taurat lisan yang terdiri dari Misyna, Talmud, dan Haggadah. Lulusan dari sini akan menjadi guru di sekolah-sekolah Yahudi tingkat dasar.(Homrighausen dan Enklaar 2013)

\section{Perjanjian Baru}

Orang-orang Kristen mula-mula juga mempunyai berita yang menarik bagi orang-orang yang terpikat dengan Gnostisisme dan agama-agama misteri. Apa yang ditekankan dalam ajaran Yesus sungguh berbeda dari sistem-sistem pemikiran yang mengingkari dunia itu. Justru karena itu, agama kristen memberikan penjelasan yang lebih menyakinkan tentang kehidupan di dunia ini, dan tidak mengajak orang untuk keluar dan memimpikan kemungkinankemungkinan hidup di dunia lain. Pemberitaan Kristen secara kokoh didasarkan 
BONAFIDE: Jurnal Teologi dan Pendidikan Kristen

www.jurnal.sttissiau.ac.id/Volume 1/Nomor 2/Desember 2020/hal. 180-196

atas peristiwa-peristiwa yang telah terjadi di dunia nyata, yakni kehidupan, kematian, dan kebangkitan Yesus menurut ajaran kristen, hidup yang baik tidak dapat dicapai dengan kemampuan manusia maupun melalui penggunaan "akal budi”. Tetapi iman Kristen menawarkan hubungan baru dan dekat dengan Allah sendiri kepada orang yang bersedia menyerahkan dirinya kepada Yesus dan membiarkan Roh-Nya mengubah hidupnya. Di samping itu orang Kristen masuk dalam suatu persekutuan yang baru yaitu jemaat baru yang memberikan manfaat kepada sesama maupun kepada diri sendiri.(Drane 2006)

Agama Kristen mewarisi Perjanjian Baru sebagai dokumen resmi yang memberikan kesaksian tentang kehidupan, kematian dan kebangkitan pendirinya, Yesus Kristus, dan tentang pembentukan jemaat Kristen mula-mula.(Baker 2010). Pengajar dalam Perjanjian Baru yaitu Yesus dan dilanjutkan oleh para Muridmurid-Nya dan juga jemaat mula-mula. Mengajar adalah tindakan intervensi Allah. Dalam Titus 2:12 : Ia mendidik kita supaya kita meninggalkan kefasikan dan keinginan-keinginan duniawi dan supaya kita hidup bijaksana, adil, dan beribadah di dalam dunia sekarang ini. 2Tim 2:2 : apa yang telah engkau dengar dari padaku didepan banyak saksi, percayakanlah itu kepada orang-orang yang dapat dipercayai, yang juga cakap mengajar orang lain. Mengajar adalah perintah Allah dalam Matius 28 : 16-20.(David Rindengan 2019). Pembinaan warga gereja dalam arti toerusting sebenarnya tidak lain adalah suatu bentuk "belajar", namun belajar secara alkitabiah selalu berwujud perbuatan. Perintah-perintah Tuhan Yesus tidak hanya merupakan ajaran tentang iman, tetapi terutama mengenai hidup kristiani kita. Yesus sendiri hidup dalam suatu persekutuan dengan murid- 
BONAFIDE: Jurnal Teologi dan Pendidikan Kristen

www.jurnal.sttissiau.ac.id/Volume 1/Nomor 2/Desember 2020/hal. 180-196

murid dan para murid diutus pergi (Mat. 10). Di bawah bimbingan sang Guru mereka memperoleh ilmu agama dan pengalaman. (Ismail 2011)

Sikap dan ajaran Yesus mengenai kaum perempuan perlu dibandingkan dengan sikap dan ajaran bangsa Yahudi mengenai hal itu pada masa Yesus di dunia. Yudaime jelas didominasi oleh kaum laki-laki yang kurang menghormati kaum perempuan. Perbedaan antara laki-laki dan perempuan sedemikian besar sehingga perempuan tidak dapat bergabung dengan laki-laki secara setara dalam pendidikan agama atau dalam ibadah. Di kalangan orang kafir pula, dengan beberapa pengecualian, perempuan dianggap lebih rendah dari pada laki-laki. Ajaran Yesus tidak hanya mempengaruhi pemahaman kita tentang misi-Nya, tetapi juga akan memberikan pengertian menyeluruh tentang kedudukan yang benar mengenai perbedaan seks dalam ajaran PB mengenai manusia.(Guthrie 2018)

Pengajar sejajar dengan nabi, namun keduanya berbeda. Tugas para pengajar lebih meneruskan ajaran-ajaran sedangkan nabi-nabi bertugas untuk menyampaikan pengertian-pengertian baru setelah mendapatkan ilham. Semua yang terdapat dalam "Injil", termasuk berbagai tradisi lisan mengenai kehidupan dan ajaran Yesus (sebelum tersebarnya catatan-catatan tertulis), mendapat perhatian khusus dari pengajar-pengajar. Kemungkinan besar mereka menangani pengajaran katekisasi bagi petobat-petobat baru. Peranan mereka dalam pembangunan jemaat mula-mula sangat penting bagi perhimpunan yang kuat yang para anggotanya berpegang pada ajaran yang benar.(Guthrie 2019)

Pengetahuan yang diwahyukan sangat penting dalam agama, dan berbeda dengan pengetahuan lainnya oleh karena adanya anggapan akan wahyu. Wahyu 
BONAFIDE: Jurnal Teologi dan Pendidikan Kristen

www.jurnal.sttissiau.ac.id/Volume 1/Nomor 2/Desember 2020/hal. 180-196

merupakan sabda Tuhan yang berisi kehendak Tuhan. Orang yang percaya terhadap wahyu menilai bahwa bentuk pengetahuan ini mempunyai kelebihan karena berasal dari sumber informasi yang mahatahu yang tidak dapat dicapai oleh metode keilmuan lainnya. Kebenaran yang diperoleh melalui sumber wahyu ini dianggap absolut dan murni.(Knight 2007)

\section{Analisis Melalui Alkitab}

Membaca secara kritis buka alternatif dari sesuatu yang disebut "membaca secara religius". Alasannya sederhana saja. Iman religius bukan hanya soal membaca. Iman religius yang berdasarkan Alkitab menyangkut perbuatan menghubungkan Allah dari pengalaman orang percaya dengan Allah yang dikenal dari Alkitab.(Sidjabat 2019). Mereka yang percaya bahwa Allah dinyatakan secara sempurna dalam Kristus biasanya memakai Perjanjian Baru sebagai pegangan untuk mengetahui apa yang diimplikasikan oleh iman mereka. (Chilton 2012)

Jadi, inilah arti mengenal Kristus dengan benar, yaitu kalau kita menerima Dia sebagaimana Ia dianugerahkan oleh Bapa, berarti bersama dengan kabar keselamatan mengenai Dia. Paulus menamakan Injil itu “ajaran tentang iman”. Iman senantiasa ada hubungannya dengan firman dan sebagaimana sinar matahari tidak dapat disentakkan dari matahari, sumbernya, iman tak dapat dipisahkan dengan dari firman itu. Jadi, jika firman dihilangkan, takkan pula ada lagi iman. Firman itu sendiri ibarat cermin, tempat iman mengamati Allah. jadi sekarang kita tahu bahwa iman itu adalah pengetahuan akan kehendak Allah. (Calvin 2013). Iman timbul dari pendengaran akan firman Tuhan sehingga siapa yang mendengar firman Tuhan dan percaya akan menerima janji Tuhan yaitu keselamatan. 
Dalam 2 Tim 3: 16: dikatakan bahwa "Segala tulisan yang di ilhamkan Allah memang bermanfaat untuk mengajar." Alkitab tidak berbicara langsung kepada manusia secara umum, tetapi hanya pada orang-orang tertentu. Alkitab juga tidak berbicara mengenai prinsip-prinsip yang kekal, melainkan perintahperintah khusus dari Allah yang hidup. Para nabi berbicara kepada umatnya sendiri. Kitab-kitab Injil mengisahkan tindakan-tindakan seseorang yang hidup di antara orang lain. Paulus menulis surat-suratnya dalam menjawab pertanyaanpertanyaan yang menjadi bagian dari pergumulan gereja. Para penulis Alkitab dapat melihat maksud Allah dalam semua peristiwa yang terjadi. Sebab itulah Alkitab menjadi dasar iman yang hidup. (Cully 2011)

Alkitab berisi nubuatan-nubuatan prediktif yang sudah digenapi. Tidak ada pertantangan dalam alkitab. Beberapa orang menyelidiki dan mengaku ada banyak pertentangan padahal bukan pertentangan melainkan satu sisi yang saling berkaitan. Alkitab Perjanjian Lama maupun Perjanjian Baru tidak ada yang salah walaupun ditulis dengan waktu yang begitu lama semua data valid dan benar. (Ryrie 1991)

Tentang pengampunan, Yesus tidak mengajarkan satu doktrin tentang hal itu, namun Ia membawa pengalaman baru tentang pengampunan kepada orangorang berdosa. Dalam Luk. 7:48, terhadap seorang perempuan berdosa yang datang di rumah Simon Yesus tidak mengatakan bahwa Allah mengampuni dia atau menerangkan bagaimana ia dapat menemukan keselamatan, tetapi Ia mengumumkan bahwa dosa-dosanya diampuni. Inilah inti ajaran etika Yesus: penyangkalan terhadap pencapaian kebenaran sendiri dan kesediaan untuk 
BONAFIDE: Jurnal Teologi dan Pendidikan Kristen

www.jurnal.sttissiau.ac.id/Volume 1/Nomor 2/Desember 2020/hal. 180-196

menjadi seperti anak-anak yang tidak memiliki sesuatu, namun harus menerima segala sesuatu.(Darmawan dan Sujoko 2013). Ahli-ahli Taurat tidak bersedia menanggalkan kesombongan mereka berkenaan dengan kebenaran mereka sendiri untuk mengosongkan diri supaya mereka dapat menerima anugerah kebenaran Allah. selama mereka memandang diri mereka benar, mereka tidak dapat menerima anugerah Allah dan hidup dalam kekudusan (Mrk. 2:27; Luk. 18:9).(Ladd 2002) Anugerah diberikan secara cuma-cuma, hanya dengan percaya, dan mengaku dengan mulut bahwa Yesus addalah tuhan dan juru selamat yang hidup.

\section{KESIMPULAN}

Dari uraian di atas nampak bahwa PAK sudah ada dalam Alkitab. Dalam Perjanjian Lama Allah menyatakan diri kepada bangsa Israel dan memberikan pengajaran melalui para nabi. Dalam Perjanjian Lama yang berpusat pada hukum Allah, Allah memberikan Sepuluh Hukum Taurat kepada umat Israel sebagai dasar pendidikan. Dalam Perjanjian Baru Yesus, murid-murid Yesus, dan juga jemaat mula-mula selalu memberikan pengajaran sebagai wujud dari intervensi Allah. Dengan demikian tidak dapat diragukan lagi bahwa Alkitab merupakan dasar bagi PAK. Melalui Alkitab orang percaya belajar hidup benar dan kudus, sehingga apa yang dilakukan orang percaya semua menurut kehendak Bapa bukan kemauan diri sendiri. Dengan mendapatkan PAK, seseorang akan hidup penuh di jalan yang benar dalam perkataan firman Tuhan. 
BONAFIDE: Jurnal Teologi dan Pendidikan Kristen

\section{DAFTAR PUSTAKA}

Baker, David L. 2010. Satu Alkitab Dua Perjanjian: suatu studi tentang hubungan teologis antara Perjanjian Lama dan Perjanjian Baru. Jakarta: BPK Gunung Mulia.

Barth, C. 2009. Theologi Perjanjian Lama 3. Jakarta: BPK Gunung Mulia.

Berkhof, H. 2004. Sejarah Gereja. Jakarta: BPK Gunung Mulia.

Boehlke, R. R. 2016. Sejarah Perkembangan Pikiran \& Praktek Pendidikan Agama Kristen 1. Jakarta: BPK Gunung Mulia.

Boehlke, Robert R. 2016. Sejarah Perkembangan Pikiran \& Praktek Pendidikan Agama Kristen 2. Jakarta: BPK Gunung Mulia.

Brotosudarmo, R. M. Drie S. 2007. Etika Kristen. Yogyakarta: ANDI Offset.

Calvin, Y. 2013. Institutio : Pengajaran Agama Kristen. Jakarta: BPK Gunung Mulia.

Carson, D.A. 1997. Gereja Zaman Perjanjian Baru \& Masa Kini. Malang: Gandum Mas.

Chilton, Bruce. 2012. Studi Perjanjian Baru Bagi Pemula. Jakarta: BPK Gunung Mulia.

Cully, Iris V. 2011. Dinamika Pendidikan Kristen. Jakarta: BPK Gunung Mulia.

Darmawan, I Putu Ayub, dan Edy Sujoko. 2013. "REVISI TAKSONOMI PEMBELAJARAN BENYAMIN S. BLOOM." Satya Widya 29 (1): 30. https://doi.org/10.24246/j.sw.2013.v29.i1.p30-39.

David Rindengan, Wem. 2019. "PENINGKATAN PROFESIONALITAS PENGAJAR AGAMA DI ERA DIGITAL MENYONGSONG REVOLUSI 4.0 (Suatu Tinjauan PAK dalam Perspektif Pedagogik Kritis)." INSTITUTIO:JURNAL PENDIDIKAN AGAMA KRISTEN. Vol. 5.

Djihad, S. D. 2012. Bagaimana Menjadi Calon Guru dan Guru Profesional. Yogyakarta: Multi Presindo.

Drane, John. 2006. Memahami Perjanjian Baru: pengantar historis-teologis. Jakarta: BPK Gunung Mulia.

Frame, John. 2009. Apologetika bagi Kemuliaan Allah. Surabaya: Penerbit Momentum (Momentum Christian Literature.

Guthrie, Donald. 2018. Teologi Perjanjian Baru 1. Jakarta: BPK Gunung Mulia.

_. 2019. Teologi Perjanjian Baru 3. Jakarta: BPK Gunung Mulia.

Hadiwijono, Harun. 2003. Iman Kristen. Jakarta: BPK Gunung Mulia.

Harianto, G.P. 2012. Pendidikan Agama Kristen dalam Alkitab \& Dunia Pendidikan Masa Kini. Yogyakarta: ANDI Offset. 
BONAFIDE: Jurnal Teologi dan Pendidikan Kristen

Hinson, David. F. 2004. Sejarah Israel Pada Zaman Alkitab. Jakarta: BPK Gunung Mulia.

Homrighausen, E.G., dan I.H. Enklaar. 2013. Pendidikan Agama Kristen. Jakarta: BPK Gunung Mulia.

Ismail, Andar. 2011. Ajarlah Mereka Melakukan: Kumpulan Karangan Seputar Pendidikan Agama Kristen. Jakarta: BPK Gunung Mulia.

Khodijah, Nyayu. 2018. Pskologi Pendidikan. Jakarta: Rajawali Pers.

Knight, George R. 2007. Filsafat Pendidikan. Yogyakarta: Gama Media.

Ladd, George Eldon. 2002. Teologi Perjanjian Baru Jilid 1. Bandung: Kalam Hidup.

Niftrik, B.J. Boland and G.C. van. 2008. Dogmatika Masa Kini. Jakarta: BPK Gunung Mulia.

Rogerson, J. 2011. Studi Perjanjian Lama Bagi Pemula. Jakarta: BPK Gunung Mulia.

Ryrie, Charles C. 1991. Teologi Dasar 1. Yogyakarta: ANDI Offset.

Sairin, Weinata. 2011. Identitas dan Ciri Khas Pendidikan Kristen di Indonesia Antara Konseptual dan Operasional. Jakarta: BPK Gunung Mulia.

Schumann, Olaf Herbert. 2015. Pendekatan pada Ilmu Agama-Agama. Jakarta: BPK Gunung Mulia.

Sidjabat, Binsen Samuel. 2019. "Kerangka Kurikulum Pendidikan Agama Kristen Berbasis Karakter di Perguruan Tinggi." Jurnal Jaffray 17 (1): 73. https://doi.org/10.25278/jj71.v17i1.314.

Simanjuntak, Junihot. 2017. Ilmu Belajar dan Didaktika Pendidikan Kristen. Yogyakarta: ANDI Offset.

Supriyadi, Supriyadi. 2016. "Community of Practitioners: Solusi Alternatif Berbagi Pengetahuan antar Pustakawan." Lentera Pustaka: Jurnal Kajian Ilmu Perpustakaan, Informasi dan Kearsipan 2 (2): 83-93. https://doi.org/10.14710/lenpust.v2i2.13476.

Utomo, Bimo Setyo. 2017. "(R)Evolusi Guru Pendidikan Agama Kristen dalam Mentransformasi Kehidupan Siswa." DUNAMIS: Jurnal Penelitian Teologi dan Pendidikan Kristiani 1 (2): 102. https://doi.org/10.30648/dun.v1i2.111.

Verkuyl, J. 2012. Etika Kristen : bagian umum. Jakarta: BPK Gunung Mulia. 